Assiut Scientific Nursing Journal

http://asnj.journals.ekb.eg

http://www.arabimpactfactor.com

\title{
Effect of Stretching Exercise on Primary Dysmenorrhea among Secondary Girl Students at Assiut City
}

Shaimaa Mohammed Goda ${ }^{1}$, Safaa Ahamed Mohamed ${ }^{2}$, Asmaa Kamal Hassan ${ }^{3}$ \& Naglaa Saad Abd El-aty ${ }^{4}$.

1. Assistant Lecture in Family and Community Health Nursing Faculty of Nursing-Assuit University, Egypt.

2. Professor of Family and Community Health Nursing Faculty of Nursing - Assuit University, Egypt.

3. Assistant Professor in Family and Community Health Nursing Faculty of Nursing-Assuit University, Egypt.

4. Assistant Professor in Family and Community Health Nursing Faculty of Nursing-Assuit University, Egypt.

\begin{abstract}
Primary dysmenorrhea is common problem among adolescent which can have negative effects on their daily activities .Aim: to evaluate the effect of stretching exercise on primary dysmenorrhea among secondary girl students at Assiut city. Subject and Methods: Quazi experimental research design was used in this study included 666 students, while the students having dysmenorrhea 515 were selected by using multi stage random sample and the program implement on169 students from Assiut city. Through a period from September 2018 to the April 2019. Four tools were used for data collection, first tool: A structured self-administered questionnaire which consisted of two parts: first part included personal characteristics, second part: knowledge about menstruation and dysmenorrhea of adolescents girls. Tools (II):Verbal Multidimensional Scoring System, tools (III): Visual Analogue scale used to assess the severity of dysmenorrhea. Tools (IV):observational checklist was used for evaluation stretching exercise. Results: The mean age of students \pm SD was $16.31 \pm 0.9$ (15.0-19.0). Regarding to the prevalence of dysmenorrhea among studied students, it was found that more than three quarters(77.3\%) were suffering from dysmenorrhea .Conclusion: It was found that there was a statistical significant difference regarding the degree of dysmenorrhea and stretching exercise. Recommendation: Improve student's awareness and knowledge about effect of physical stretching exercise by incorporating this topic into curriculums.
\end{abstract}

\section{Keywords: Adolescent, Primary Dysmenorrhea \& Stretching Exercise.}

\section{Introduction}

Adolescence is a period from childhood to adulthood. It is described by rapid physical, biological, hormonal, endocrinal, emotional and mental growth with a change a from complete dependence to independence (David,2014)

Menstruation is a natural phenomenon that occurs during the reproductive ages of every woman. Most females experience some degree of pain and discomfort during their menstrual periods which could have major effects on their daily activities (Farotimi, et al., 2017).

One of the major physiological changes that occur among adolescents is the onset of menarche, which is frequently related with problems of irregular menstruation, excessive bleeding and dysmenorrhea. Of these, dysmenorrhea, recurrent, cramping lower abdominal pain during menstruation is one of the common problems experienced by many girl (Patil et al., 2019) .

Dysmenorrhea is a painful sensation in the lower abdomen often accompanied by other biologic symptoms, including fatigue, dizziness, sweating, headaches, backache, nausea, vomiting, diarrhea, all occurring just before or during the menses (Gebeyehu et al., 2017).

Dysmenorrhea is primary or secondary on the base of absence or presence of pathology. Primary dysmenorrhea is seen only in ovulatory cycles typically developing within 6 to 12 months of menarche with no underlying pathology or organic base. Secondary dysmenorrhea is commonly due to pelvic pathology and it is not common in adolescent girls (Patel et al., 2017).

Dysmenorrhea is a common indicator secondary to several reproductive disorders, but it is also considered in most females as a primary form of illness. The primary dysmenorrhea is somewhat frequent in young women and remains with a good prognosis; even still it is associated with low quality of life (Bernardi et al., 2017).

The pain of primary dysmenorrhea and the symptoms that may be associated with it are due to elevated prostaglandin levels. These Prostaglandins cause muscle contractions in the uterus, which cause pain and reduce blood flow and oxygen to the uterus. The levels of prostaglandin F2 $\alpha$ are especially high during the first two days of menstruation in females with primary dysmenorrhea ( Kaur, et al., 2015). 
Management of dysmenorrhea according to its type, in primary dysmenorrhea ,some methods are used as hot application, balanced nutrition, regular exercise, enough sleep, massage besides medicine treatment. Acupuncture .However, the treatment of secondary dysmenorrhea was planned direct to eliminate pathology under pain (Kizilirmak et al., 2019).

Exercises are an integral part of normal life for many women. It help in reducing pain, relieving stress, elevating mood and improving health (Kapoor et al., 2017 ).

Stretching exercise are important to reduce Physical and Psychological symptoms of primary dysmenorrhea such as lack of concentration, behavioral changes, breast pain and anxiety .They also improve flexibility, restore mobility, relax uterine muscles and maintain good abdominal tone. All of these are acute effects of stretching exercises. Long term effects of continuous stretching exercises are increase in range of joints and increase in length of muscles (Kiranmayi, et al., 2016).

Nurses emphasize, health promotion, wellness enhancing strategies and illness prevention activates as important forms of health care because they assist client in maintain and improve health. Health program aimed to improve a student's level of wellness in all dimensions, health program such as healthy lifestyle, nutrition, exercise, family relationships and coping with stress and adaptations behaviors (Ahmed, 2016)

The community health nurse has an important task in conducting school health programme and educating adolescent girls as well as community regarding the different non-medical measures and its effectiveness in controlling menstrual pain perception.(Hennegan \& 2016).

\section{Significance of the study}

Primary dysmenorrhea is a painful menstruation that occurs in the absence of any significant pelvic pathology. It usually develops after first two years of the menarche. it is one of most common problem among adolescents and the typical age range of occurrence for primary dysmenorrhea is between 17 and 22 years (Mole, 2017, Renuka \& Jeyagowri, 2015).

In Egypt, there was a high prevalence rate of dysmenorrhea $(66.0 \%)$ with $(28.4 \%)$ for mild pain, $24.3 \%$ for moderate pain and $13.3 \%$ for severe pain (Nooh, 2016).

Dysmenorrhea is frequently associated with sickness absenteeism, decrease in academic performance, and decrease in physical and social activities in adolescents. In spite of the frequency and severity of dysmenorrhea, most girls do not seek medical treatment for this condition because they feel it is a normal part of the menstrual cycle. Therefore, dysmenorrhea affects not only the untreated person but also her family, her social life, and national economics as well ( Kumar et al., 2016).

Many parts of the developing countries, a culture of silence surrounds the topic of menstruation and related issues; as a result many young girls lack appropriate and sufficient information regarding dysmenorrhea and exercise (Esike et al., 2015).

\section{Aim of study to}

Evaluate the effect of Stretching Exercise on Primary Dysmenorrhea among Secondary Girl Students at Assiut City.

\section{Research Hypothesis}

After application and practicing of stretching exercise, pain of dysmenorrhea will be decreased

\section{Subjects \& Method \\ Research design}

Quazi experimental research design was used in this study

\section{Setting of the study}

Assiut city includes (7) governmental secondary girls school included (8049) students which divided into east (3) and west (4).The study was conducted on randomly four secondary girls schools at Assiut city, two of them were general secondary schools, namely (El- waledia secondary girls, El khayat secondary school girls ) and two were technical secondary schools namely (Industrial secondary school girls , Secondary commercial Girls

\section{Sample}

Multi stage random sample was used in this study, First stag: (5) Were general secondary girls schools included (3300) represented ( $41 \%$ ) of total number of Assiut secondary schools and (2) of them were technical secondary girls schools included (4749) students, represented ( 59\%) of total number of students. Four secondary governmental schools for girls were selected randomly. The total number of students in selected randomly schools were (6301) students. Total number of students in selected technical schools was(4749)students, represented about $(75.4 \%)$ of total number of students in the sample while the total number of students in selected general secondary school was(1552 ) students, represented about $(24.6 \%)$ of total number of students in the sample

Second stage: Total number of girls students in Assiut schools were (8049). with software EPI /Info, version, 3 with $99 \%$ confident interval (CI) and use the prevalence of dysmenorrhea under study (66\%) included in the calculation. The sample size found to be (555) and increase $20 \%$ to avoid drop out and refuse .The final sample size was be 666 students and whom selected randomly from each grade. 
Proportion sample distributed to each school according to number each school

\begin{tabular}{|l|c|c|c|}
\hline \multicolumn{1}{|c|}{ School name } & $\begin{array}{c}\text { Total } \\
\text { number } \\
\text { students }\end{array}$ & $\begin{array}{c}\text { Sample } \\
\text { size }\end{array}$ & Percent \\
\hline $\begin{array}{l}\text { El khayat secondary } \\
\text { school girls }\end{array}$ & 1007 & 107 & $16 \%$ \\
\hline $\begin{array}{l}\text { El-waledia } \\
\text { secondary girls }\end{array}$ & 545 & 57 & $8.6 \%$ \\
\hline $\begin{array}{l}\text { Industrial } \\
\text { secondary school }\end{array}$ & 1500 & 158 & $23.8 \%$ \\
\hline $\begin{array}{l}\text { Secondary } \\
\text { commercial Girls }\end{array}$ & 3249 & 344 & $51.6 \%$ \\
\hline \multicolumn{1}{|c|}{ Total } & 6301 & 666 & $100 \%$ \\
\hline
\end{tabular}

After calculation of the sample the classes were selected randomly by using systematic random sample. All grades (first, second and third grade) were included in the study.

The total sample (666) students girls were subjected for assessment .It was observed that (169) student out of the previous total number of studied sample had dysmenorrhea

Primary dysmenorrhea is defined as Primary dysmenorrhea is a painful menstruation that occurs in the absence of any significant pelvic pathology. It usually develops after first one or two years of the menarche (Mole, 2017)

\section{Exclusion criteria}

1. Adolescent girls with irregular menstrual periods.

2. Adolescent girls who were following any other pharmacological drugs.

3. Adolescent girls with regular physical exercise

Tools of the study

Four Tools were used to collect data for this study:

Tool I: A structured self-administered questionnaire: It was designed and developed by the research team after reviewing of different researches. It was covered two parts:

Part 1: Personal characteristics for students include: name, age, academic year, school type, residence, father's education, mother's education, fathers' occupation , mothers' occupation.

Part 2: knowledge about menstruation and dysmenorrhea of adolescent girls about the following:-

1. Menstrual history as age of menarche, duration of menstruation, menstrual interval, regularity of menstruation, the number of pads used per day , type of pad used (El-Hameed, 2011).

2. History of dysmenorrhea and Pain associated menstruation (Aboushady \& El-saidy, 2016, Gebeyehu et al., 2017)

3. Question about knowledge about of menstruation and dysmenorrhea such as definition of menstruation, Age at menarche ,period of menses, physiology of menses , the sources of knowledge about menstruation, definition of dysmenorrhea, types of dysmenorrhea (Aboushady \& El-saidy, 2016 \& Gebeyehu, et al., 2017)

Score system for knowledge, correct response was scored (1) grade and zero for the incorrect the score of knowledge each item summed -up then converted into a percent score $($ poor $=$ score $<50 \%$, fair $=$ score $50-70 \%$ and good $=$ score $>70 \%$ ( Kamel, 2019)

Tools(II): Verbal Multidimensional Scoring System(VMS) for assessment the severity of dysmenorrhea, The scoring system ranges from 0-3 grade for evaluating the pain effect to working ability ,the systemic symptoms and whether analgesia is required or not (Direk \& Khosravi, 2012)

Tools (III): Visual Analogue scale used for assessment of dysmenorrhea severity, $10 \mathrm{~cm}$ blank line used to describe the extremes of pain. The adolescent females are asked to place mark on the line that indicate the pain experienced. The scoring system ; zero(0) indicate no pain, graded from $1-3 \mathrm{~cm}$ reflect mild pain ,graded from $4-7 \mathrm{~cm}$ for moderate pain and graded from $8-10 \mathrm{~cm}$ for severe pain. The scale was used before implementation of stretching exercise to assess dysmenorrhea and then re-used one month later to assess effectiveness stretching exercise on reducing pain of dysmenorrhea (Aboushady and El-saidy ,2016) Tools (IV): Observational checklist was used for applying stretching exercise.This tools consisted from 6 items each girls trained to perform the procedures. Which used to assess the effect of stretching exercise on reducing pain of dysmenorrhea (Aboushady \& El-saidy, 2016)

\section{Validity}

The tools were transferred to Arabic language and reviewed to ascertain their validity by five experts in medical and nursing sciences, who reviewed the instrument for clarity, relevance, comprehensiveness, understanding and applicability.

\section{Reliability}

A reliability test was carried out by the researcher in order to examine the internal consistency of its questions. it was done during the pilot study before starting of data collected on $10 \%$ (67) of adolescent students. The value of Cronbach's alpha was $=0.834$ for knowledge

The study phases

Administrative phase

An official approval letter was obtained from the dean of the Faculty of Nursing, Assiut University to Assiut Directorate of Education and from Directorate of education to Central Agency for public mobilization and statistics after that to Centralized Management of Security. Finally, to directors of the schools. The letters included a permission to carry out the study. 
Pilot study

Pilot study was carried out before starting of data collection on $10 \%$ of adolescent students; who included in the sample. It aimed to test the clarity of the tools and estimate the required time to fill the questionnaire.

\section{Ethical consideration}

The researcher followed all the ethical issues in conducting the research. Consent was secured orally from the participants who were willing to participate in the study. The participants were informed that participation in this study is voluntary; they can withdraw at any time during the study without giving reasons. The researcher have explained the aim of the study to all school students in the study sample .They reassured that any obtained information would be strictly confidential.

Data collection phase (Assessment phase)

- An explanation of the purpose of the research was done to directors of schools and the researcher gave the directors of each setting a copy of official letter and the researcher was taking a copy of study schedule of the selected grades .Also the purpose of the study was explained to studied students to gain their cooperation before starting data collection. The researcher started to collect data from the end of September 2018 to the end of November 2018 (9 weeks) from (666) students who accepted to participated in this study then stopped and continued after mid-year vacation to first of April ,2019

- The self-administered questionnaire filled by the students themselves. The length of each interview was (20-30) minutes. The researchers were available in the class to answer any questions and further explanations.

- The data was collected in (two days/ week ) with average number 37- 42 students /day.

- The Verbal Multidimensional Scoring System and Visual Analogue scale were used for assessment of dysmenorrhea and which indicated that total number of students having dysmenorrhea (169)

Implementation phase

It was done applying stretching exercise .checklist regarding stretching exercise was done immediately for students having dysmenorrhea to assess students' performance for stretching exercise

Evaluation phase

The evaluation was done through immediate post test and late post test

The educational program

The educational program has been developed by the research team and according to students' needs which detected from pretest included the theoretical part based on the relevant literatures, and the procedure of stretching exercises. The educational program presented

Objectives of the program

General objectives of the program

Evaluate the effect of stretching exercise on minimizing pain of dysmenorrhea among adolescent girls

\section{Specific objectives to}

1- Assess students' knowledge about menstruation and dysmenorrhea

2- Implement health education program regarding dysmenorrhea

3- Apply stretching exercise

4- Evaluate the effectiveness of students exercise on reducing pain of dysmenorrhea

I Assessment phase

Based on pre test assessment of students' knowledge about menstruation and dysmenorrhea .which denotes knowledge deficit, so the program were prepared to improve students' knowledge

\section{II-Planning phase}

The sessions and time of the program decided. The studied sample student having dysmenorrhea were divided into two groups case group which include student from two school (El-waledia secondary girls and Industrial secondary school) and control group which include students from others two schools which (El khayat secondary school girls and Secondary commercial Girls). Other facilities were checked and arranged during this phase as the teaching place, teaching methods, audiovisual aids and handout.

Teaching place the program was conducted in available places( classroom and nursery school health room ) in each selected school. This arrangement was done with the director of the schools.

Teaching methods and materials: It was prepared before implementing the educational program to prepare simple teaching methods to be used; as lecture, discussion, and brainstorming and used media as picture, handouts, posters, blackboard

\section{III- Implementation phase}

The researchers collected the data (pretest, implementation of program, immediate posttest and late posttest) during the period from the end of September 2018 to first of April 2019

After the researcher finished the assessment, the questionnaires was examined to identify the students was suffering from dysmenorrhea in four previous school and then the participants who having dysmenorrhea was divided to two groups in four schools (case group represent two school and control group involve another two school) the studied groups were randomized selected to apply the program about menstruation, dysmenorrhea and the 
stretching exercise was be implemented for study group who having dysmenorrhea by performing demonstration and re demonstration for exercise .

El-waledia secondary girls

The data collected in the morning 2day/weeks .Total number 40 students divided into three groups arranged from 13-15 students . The total numbers of sesstions for each group were 2 sessions. Every group was received session / day .every session took 90 min. The sessions were given according to the previous program phases

\section{Industrial secondary school}

The data collected in the evening 4 day/weeks .Total number 129 students divided into sixth groups arranged from 20-22 students . The total number of sessions for each group were 2 sessions. Every group was received session / day every session took 90 min. The sessions were given according to the previous program phases

late post test done after one month of application of program among four previous schools

\section{Evaluation stage}

The evaluation was done through

1. Immediate posttest which done immediately after implementing the program to assess adolescent girl' knowledge about menstruation and dysmenorrhea and to assess students' performance of stretching exercise was done by using observational checklist

2. late post test which was done after one month of completing the educational program to assess adolescence girl' knowledge and evaluate the effect of stretching exercise on minimizing of dysmenorrhea by using multidimensional scale and visual analogue scale

\section{Statistical Analysis}

Data entry and data analysis were done using SPSS version 22 (Statistical Package for Social Science). Data were presented as number, percentage, mean and standard deviation. Chi-square was used to compare between qualitative variables. P-value considered statistically significant when $\mathrm{P}<0.05$. 


\section{Results}

Table (1): Distribution of studied students regarding to personal characteristics in Assuit City, 2019.

\begin{tabular}{|c|c|c|}
\hline personal characteristics & No. (666) & $\%$ \\
\hline \multicolumn{3}{|l|}{ School Type } \\
\hline General secondary school & 164 & 24.6 \\
\hline Technical secondary school & 502 & 75.4 \\
\hline \multicolumn{3}{|l|}{ Age: (years) } \\
\hline 15 & 119 & 17.9 \\
\hline 16 & 304 & 45.6 \\
\hline $17-19$ & 243 & 36.5 \\
\hline Mean \pm SD & & \\
\hline \multicolumn{3}{|l|}{ Academic year } \\
\hline First & 329 & 49.4 \\
\hline Second & 200 & 30.0 \\
\hline Third & 137 & 20.6 \\
\hline \multicolumn{3}{|l|}{ Residence } \\
\hline Urban & 422 & 63.4 \\
\hline Rural & 244 & 36.6 \\
\hline \multicolumn{3}{|l|}{ Fathers' education } \\
\hline Illiterate & 43 & 6.5 \\
\hline Read \& write & 93 & 14.0 \\
\hline Primary & 66 & 9.9 \\
\hline Preparatory & 58 & 8.7 \\
\hline Secondary & 264 & 39.6 \\
\hline University & 142 & 21.3 \\
\hline \multicolumn{3}{|l|}{ Mother' education } \\
\hline Illiterate & 125 & 18.8 \\
\hline Read \& write & 93 & 14.0 \\
\hline Primary & 55 & 8.2 \\
\hline Preparatory & 67 & 10.1 \\
\hline Secondary & 214 & 32.1 \\
\hline University & 112 & 16.8 \\
\hline \multicolumn{3}{|l|}{ Father's occupation: } \\
\hline Governmental employee & 335 & 50.3 \\
\hline Free business & 168 & 25.2 \\
\hline Skilled worker & 59 & 8.8 \\
\hline Retired & 61 & 9.2 \\
\hline \multicolumn{3}{|l|}{ Mother 's occupation: } \\
\hline Housewife & 507 & 76.1 \\
\hline Employee & 151 & 22.7 \\
\hline
\end{tabular}

* 43 Fathers were dead 8 mothers were dead 
Table (2): Distribution of studied students regarding to their menstrual history in Assiut City, 2019.

\begin{tabular}{|c|c|c|}
\hline Menstrual History & No. $(666)$ & $\%$ \\
\hline \multicolumn{3}{|l|}{ Age of menarche: (years) } \\
\hline $11-13$ & 523 & 78.5 \\
\hline $14-16$ & 143 & 21.5 \\
\hline $12.70 \pm 1.10(11.0-16.0)$ & & \\
\hline \multicolumn{3}{|l|}{ Average menstrual period } \\
\hline$<3$ days & 28 & 4.2 \\
\hline 3-4 days & 356 & 53.5 \\
\hline 5- 7 days & 220 & 33.0 \\
\hline More than 7 days & 34 & 5.1 \\
\hline Not known & 28 & 4.2 \\
\hline \multicolumn{3}{|l|}{ Regularity of menstrual cycle } \\
\hline Regular & 500 & 75.1 \\
\hline Irregular & 166 & 24.9 \\
\hline \multicolumn{3}{|l|}{ Menstrual interval } \\
\hline$<28$ days & 95 & 19.0 \\
\hline 28- 30 days & 307 & 61.4 \\
\hline 31-35 days & 69 & 13.8 \\
\hline$>35$ days & 29 & 5.8 \\
\hline \multicolumn{3}{|l|}{ Delayed menstrual cycle every month } \\
\hline Yes & 425 & 63.8 \\
\hline No & 241 & 36.2 \\
\hline \multicolumn{3}{|l|}{ Number of bads changed daily } \\
\hline $1-3$ & 545 & 81.8 \\
\hline$>3$ & 121 & 18.2 \\
\hline $2.72 \pm 0.97(1-6)$ & & \\
\hline \multicolumn{3}{|l|}{ Types of towel used during menstruation } \\
\hline Sanitary ready towel & 647 & 97.1 \\
\hline Not reusable towel & 10 & 1.5 \\
\hline A piece of cloth to be reused after washing well and exposed to sunlight & 9 & 1.4 \\
\hline
\end{tabular}

Table (3): Effect of stretching exercise on reducing pain of dysmenorrhea among adolescent cases in Assiut City, 2019.

\begin{tabular}{|l|c|c|c|c|c|}
\hline \multirow{2}{*}{\multicolumn{1}{|c|}{ Degree of pain }} & \multicolumn{2}{|c|}{ Pre-test (n= 169) } & \multicolumn{2}{c|}{ Late post test (n= 169) } & \multirow{2}{*}{ P-value $^{\mathbf{2}}$} \\
\cline { 2 - 5 } & No. & $\mathbf{\%}$ & No. & \% & \\
\hline NO pain & 0 & 0.0 & 74 & 43.8 & \multirow{2}{*}{$0.000^{*}$} \\
\hline Mild pain & 64 & 37.9 & 78 & 46.2 & \\
\hline Moderate pain & 55 & 32.5 & 16 & 9.5 & \\
\hline Sever pain & 50 & 29.6 & 1 & 0.6 & \\
\hline
\end{tabular}

$P$-value ${ }^{2}$ : between pretest and late post test

Table (4): Effectiveness of stretching exercise on reducing pain of dysmenorrhea among case and control study After intervention in Assiut,2019

\begin{tabular}{|c|c|c|c|c|c|}
\hline \multirow{2}{*}{ Degree of pain } & \multicolumn{2}{|c|}{$($ case $)(n=169)$} & \multicolumn{2}{|c|}{$($ control $)(n=346)$} & \multirow{2}{*}{$P$-value ${ }^{1}$} \\
\hline & No. & $\%$ & No & $\%$ & \\
\hline After intervention & & & & & \multirow{5}{*}{$0.000 *$} \\
\hline NO pain & 74 & 43.8 & 0 & 0.0 & \\
\hline Mild pain & 78 & 46.2 & 66 & 19.1 & \\
\hline Moderate pain & 16 & 9.5 & 103 & 29.8 & \\
\hline Sever pain & 1 & 0.6 & 177 & 51.2 & \\
\hline
\end{tabular}




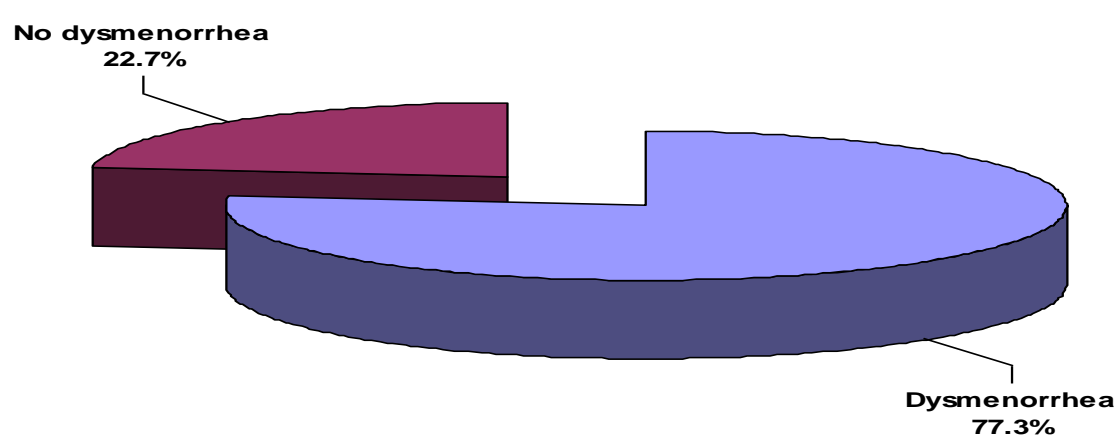

Figure (1): Distribution of the studied students regarding their suffering from dysmenorrhea in Assiut City, 2019.

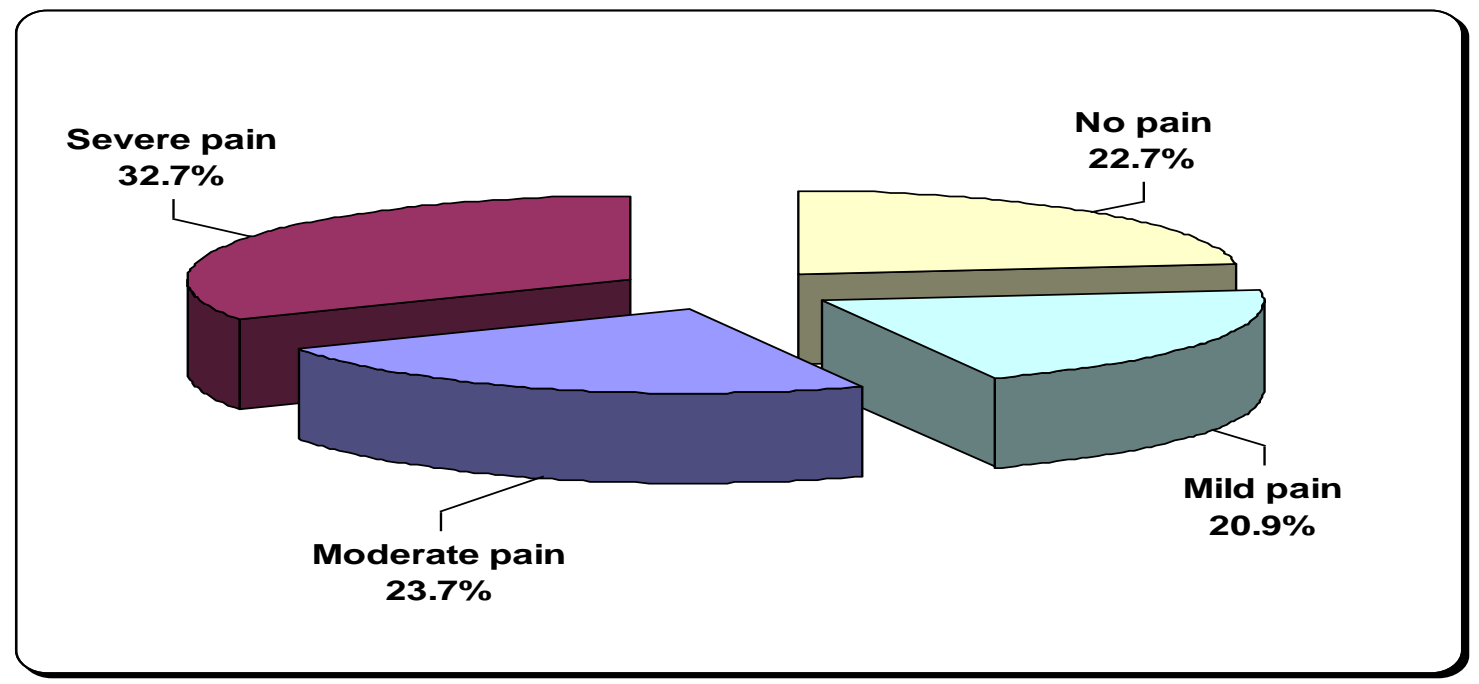

Figure (2): Degree of pain related dysmenorrhea among studied students in Assiut city, 2019.

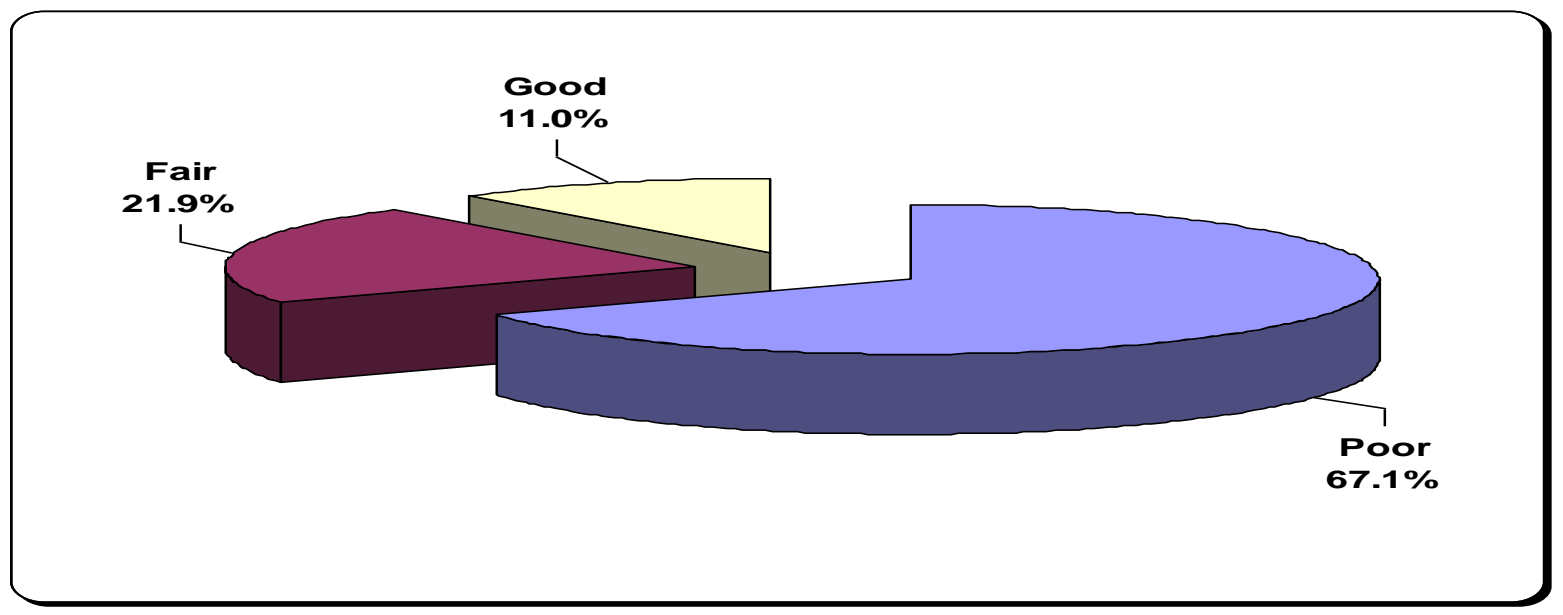

Figure (3): Total score of knowledge regarding menstruation and dysmenorrhea among studied students in Assiut city, 2019. 


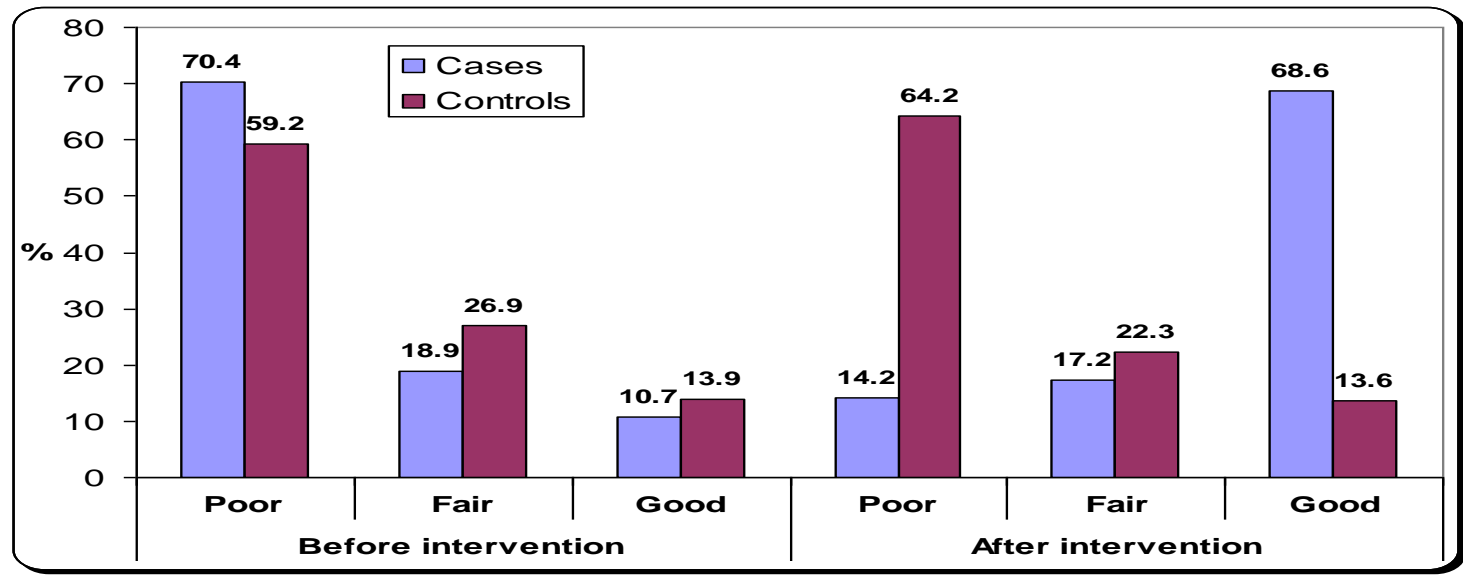

Figure(4):Relation between total score of knowledge among case and control group before and after the intervention in Assiut city, 2019.

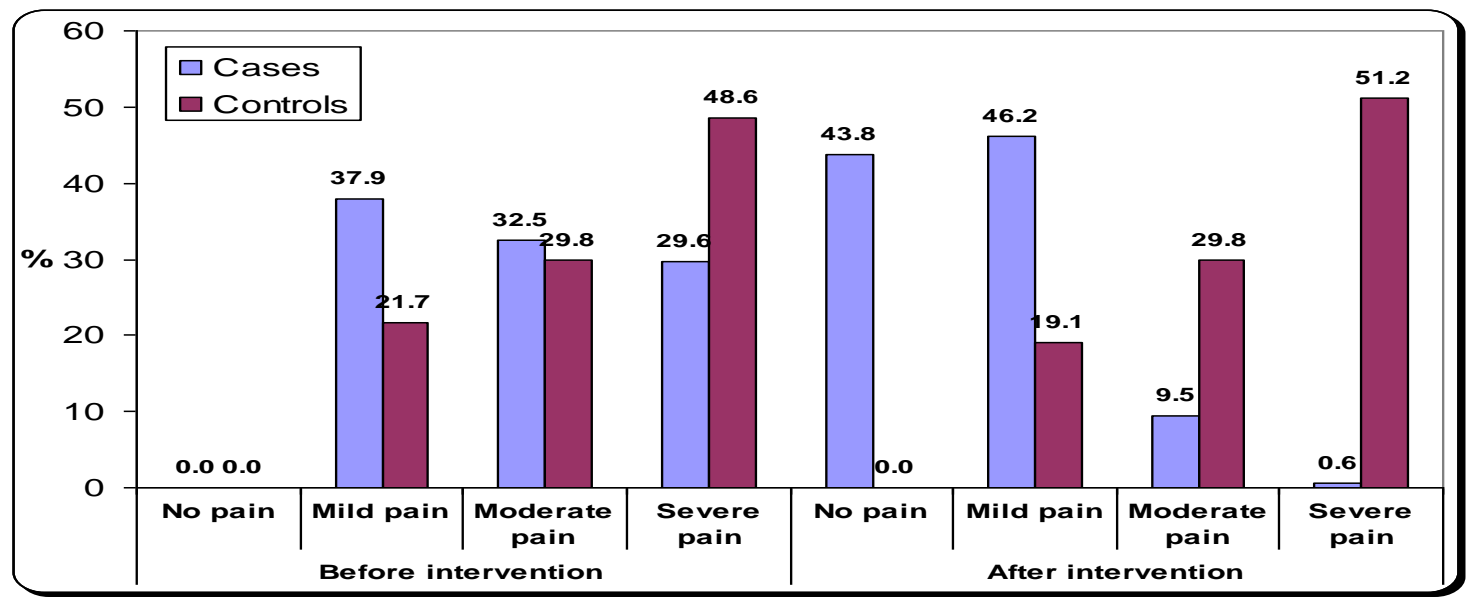

Figure (5): Effect of stretching exercise on reducing pain of dysmenorrhea among case and control group in Assiut City, 2019

Table (1): Shows personal characteristics of studied students. It was observed that the age group 16 years represent more than two fifths $(45.6 \%)$ with mean age \pm SD $16.31 \pm 0.91 \quad(15.0-19.0)$. Regarding to Academic year, nearly half $(49.4 \%)$ of studied students were in first grade and less than one third $(30.0 \%)$ of them were in the second grade. Concerning to residence, it was found that about two thirds $(63.4 \%)$ of studied students were from urban area.

Table (2): Shows distribution of studied students regarding to their menstrual

history, it was revealed that more than two thirds ( $78.5 \%$ ) of the studied students their menstruation started in age 11-13 years. Regarding to the average length of menstrual period, it was observed that more than half $(53.5 \%)$ of them their ranged from 3-4 days. Also it was found that slightly more than three quarters $(75.1 \%)$ of them had regular menstrual periods. According to number of bads changed daily, the majority $(81.8 \%)$ of studied students mentioned that they used 1-3 bads per day.

Table (3): Represents degree of pain of dysmenorrhea among intervention studied students in pre-test and late posttest .It was revealed that there was a statistical significant difference regarding the degree of pain in pre and late post tests among intervention groups ( $\mathrm{p}$-value $=0.000$ )

Table (4): It was revealed that there was a statistical significant difference between degree of pain after intervention in case and control groups $(0.000 *)$

Figure (1): Illustrates distribution of studied students according to their suffering from dysmenorrhea. It was found that more than three quarters $(77.3 \%)$ of students were suffering from dysmenorrhea

Figure (2): Shows that about one thirds (32.7\%) of studied student suffering from dysmenorrhea having severe pain and less than one quarter (20.9\%) of them reported mild pain 
Figure (3): This figure demonstrates total score of students' knowledge about menstruation and dysmenorrhea. It was found that more than two thirds $(67.1 \%)$ of studied students had poor knowledge, while less than one quarter $(21.9 \%)$ of them had fair knowledge .

Figure (4): Show the relation between total score of knowledge among case and control group before and after intervention .It was clear that $(10.7 \%)$ before intervention among cases students were had good knowledge, while after intervention their knowledge improved to be $68.6 \%$.Also it shows that round $13.6 \%$ had good knowledge among control group after intervention.

Figure (5): Figure demonstrates that more than one quarter $(29.6 \%)$ of case students having severe pain before intervention, while only $(0.6 \%)$ of them having severe pain after intervention

\section{Discussion}

Primary dysmenorrhea is one of the most common and important health problems, especially among adolescent females and it interferes with daily activities and affects their physical and emotional aspects and has a negative impact on quality of life. (Saeed, 2018 )

The present study aimed to evaluate the effect of stretching exercise on minimizing pain of dysmenorrhea among adolescent girls

present study shows that the mean age group of students' were $16.31 \pm 0.91$, it was ranged from 15:19, these results agree with (Charan et al., 2019) who conducted a study about knowledge and level of distress regarding primary dysmenorrhea among adolescent girls at Amritsar and they reported that the age of student ranged from 16:20 years and the mean age of students was $16.84 \pm 2.044$.

Also, these results in the same line with Kumar et al., (2016) who conducted study about dysmenorrhea among higher secondary school girls, Manipur : Across sectional and they reported that students age range from 15-19 years old and the mean age of students was $16.78 \pm 0.90$

Concerning to Academic year of the studied students, the current study showed that around half of the studied students were studying in first year while only less than one fifth of them were third year. This may be explained by the first academic years more committed attended in school related to educational curriculum evaluation every month.

This results contrast with (Khodarami et al., 2015) who study the severity of dysmenorrhea and its relationship with body mass index among female adolescents , Iran and found that the majority of studied students were studying in the first and third year .
The current study indicated that the mean age of menorrhea $12.70 \pm 1.10$.This finding in accordance with Charan, et al., (2019) who reported that the mean age of menarche $12.37 \pm 871$.

In addition, these results supported by Aboushady \& El-saidy, (2016) who conducted study about effect of home based stretching exercises and menstrual care on primary dysmenorrhea and premenstrual symptoms among adolescent girls in Egypt and they reported that the mean age of menarche was $12.5 \pm$ 2.08 .

Regarding the number of pads changed daily and types of towel used during menstruation, the present study cleared that the majority of studied student mentioned ranged from 1-3number / day changed bad and the vast majority of them reported they used sanitary ready towel .This may be attributing to the influence of television which had increased their awareness regarding the availability and use of sanitary pads. These results disagree with Hakim et al., (2017) who study Across sectional study on the knowledge ,attitude and practices toward menstrual cycle and its problems of girls in India and found that more than two fifths of students were use sanitary pad only.

According to prevalence of dysmenorrhea, more than three quarter of students suffering from dysmenorrhea. Also Mohammed, (2019) who conducted study about dysmenorrhea and associated factors among secondary school students in Ethiopia and reported that more than three quarters of the students were suffering from dysmenorrhea .These results are contrary with George et al., (2014) who study dysmenorrhea among adolescent girls characteristics and symptoms experienced during menstruation in India and finding that less than two thirds of students were suffering of dysmenorrhea, it may be attributed to the variation could be associated with ethnic, sociocultural factors, cultural background, and geographical location

As regard to degree of pain. The present study showed that about one third of students experienced severe pain, more than one fifth had moderate pain and less than one quarter had mild pain .This finding contrast with Kumar, et al., (2016) who conducted study about dysmenorrhea among higher secondary school girls, Manipur and found was mild in about one third, more than two fifths as moderate pain and sever dysmenorrhea pain was experienced by about one fifth . May be related to the existence of different cultural perception and responses to various gradients of pain.

In addition, the current study demonstrated that slightly more than two thirds of studied students had poor knowledge and less than one quarter of them had fair knowledge, it may explained by lack of 
proper health education programs in the school, which focused on the menstrual health and hygiene among girls. Additionally, this could also be due to the assumption that some of these girls were still very young provided that issues of sexuality still have cultural restrictions in our society making them vulnerable to limited sources of information about this issue

This results disagree with Harum et al., (2016) who carried study about correlation of students' knowledge level about menstrual with dysmenorrhea handling effort in Nigeria and found less than third(32.3\%) of students were poor and two fifths of them had fair knowledge.

Regarding to effected educational program on students' knowledge, the present study shows that the studied students' knowledge were improved in immediate post test. Also the majority of them had good knowledge in immediate post test and the minority of them decline knowledge in late post test ,it could be interpreted that the student in the period of post test they were preparing for the final exam at the school, which negatively affecting on their physical activity and its related knowledge

The current results in agreement with Haque et al., (2014) who conducted study in Bangladesh about the effect of a school-based educational intervention on menstrual health among adolescent girls and they reported that that knowledge and beliefs regarding menstrual hygiene were low before implementation of the program. After implementation, there was a significant increase in knowledge among the adolescents.

The present study revealed that there was a statistical significant difference regarding the degree of pain in pre and late post tests among intervention groups after stretching exercise $(\mathrm{p}$-value $=0.000)$ this results may be explained by the increase in blood flow and metabolism of the uterus during exercise which may be effective in the reduction of dysmenorrheal symptoms. Stress tends to enhance sympathetic activity and may increase menstrual pain by exacerbating uterine contraction. Exercise may decrease this sympathetic activity and relive the stress through release of endorphins, substances produced by the brain that raise the pain threshold, so reducing symptoms Kaur et al., (2015).

This finding supported with Aboushady \& El-saidy, (2016) who reported that a significant reduction in their pain after stretching exercise intervention. $(\mathrm{P}<0.001)$. Also these results was similar with (Fallah \& Mirfeizi, 2018 )who study the quality and quantity of primary dysmenorrhea affected by Physical exercises among Iranian Students and who found that stretching exercises which are effective in reducing pain in females with primary dysmenorrhea $(\mathrm{P}<0.05)$

These results of the present study concur with Khare \& Jain, (2015) who study effect of different exercise techniques on primary dysmenorrhea among higher secondary school girls in India and who reported that the reduction of pain was found more a significant difference between case and control groups regarding intensity of pain after stretching exercise intervention $(\mathrm{p}<0.0014)$.

\section{Conclusion}

Based on the results of the present study, it can be concluded that

The prevalence of dysmenorrhea among studied students was more than three quarters. More than two thirds of studied student had poor level of knowledge regarding menstruation and dysmenorrhea in pretest while after implementation the education program their knowledge was improved. There was statistically significant difference between student's knowledge in pre test and post test. Also, stretching exercise was more effective in reducing pain of dysmenorrhea

\section{Recommendations}

Based on the results of the present study, the following recommendation are suggested:

- Improve student's awareness and knowledge about effect of physical stretching exercise by incorporating this topic into curriculums.

- Increases awareness of students regarding menstruation and physical exercise to relieve pain of dysmenorrhea through mass media.

- Further research's about menstruation, dysmenorrhea and stretching exercise to improve awareness of adolescent girls.

- Further is needed for this study in different students to raise the ability of generalize the results of stretching exercise.

\section{Reference}

1. Aboushady, R., \& El-saidy T., (2016): Effect of Home based Stretching Exercises and Menstrual Care on Primary Dysmenorrhea and premenstrual Symptoms among Adolescent Girls , Journal of Nursing and Health Scince, 5 (2):10-17.

2. Ahmed W., (2016): Health promoting and Quality for Nursing Students at Assuit University, Submitted For Partial Fulfillment of the Requirements for doctrorate Degree in Community Health Nursing.

3. Bernardi M., Lazzeri L., Perelli F., Reis F., \& Petraglia F., (2017): Dysmenorrhea and 
related disorders ,Jounal F1000 rsearch,5(6): 1645

4. Charan G., S,Kaur A., Joshi U., \& Joshi P., (2019): knowledge and level of distress regarding primary dysmenorrhea among adolescent girls at Amritsar, International Journal of Health Science \& Research ,9(8):333:341.

5. David D., (2014): study to assess the knowledge regarding home remedies to relieve dysmenorrhea among adolescent girls in selected schools of Ludhiana Punjab ,International Journal of Current Research ,6(10):9279-9282.

6. Direk V., \& Khosravi A., (2012): Comparison of verbal multidimensional scoring system (VMS) with Visual Analogue Score (VAS) for evaluating of shiraz Thymus Vulgaris on menstrual pain ,journal of pharmaceutical and biomedical science ,23:1-5.

7. El-Hameed N., (2011): knowledge and attitude towards dysmenorrhea and menstrual hygiene among adolescent girls in some nursing school at El-Minia Governorate, Submitted for Partial Fulfillment of the Requirements for Master Degree, in obstetrical and Gynecological Nursing.

8. Esike J., Farotimi A., Ojediran T., \& Nwozichi C., (2015): Effects of care practices towards dysmenorrhea among female students in South-West Nigeria ,International of Health and Allied science , 4 (2): 121-123.

9. Fallah F., \& Mirfeizi M., (2018): quality and quantity of primary dysmenorrhea affected by Physical exercises among Iranian Students, International Journal of Women's Health and Reproduction Sciences 6(1):60-66.

10. Farotimi A., Esike J., Nwozichi C., Ojediran T., \& Ojewole F., (2017): Knowledge, Attitude, and Healthcare-Seeking Behavior towards Dysmenorrhea among Female Students of a Private University in Ogun State, Nigeria, Journal of Basic and Clinical Reproductive Sciences , 4(1):33-38.

11. Gebeyehu M., Mekuria A., Tefera Y., Andarge D., Yabsira Belayneh Debay Y., Bejiga G., \& Gebresillassie B., (2017): Prevalence, Impact, and Management Practice of Dysmenorrhea among University of Gondar Students, Northwestern Ethiopia, International Journal of Reproductive Medicine ,6(8):1-8.

12. George N., Priyadarshini S., \& Shetty S., (2014): Dysmenorrhea among adolescent girlscharacteristics and symptoms experienced during menstruation, Nitte University Journal of Health Science,4(1) 35:45.
13. Hakim A., Shaheen R., \& Tak H., (2017): Cross sectional study on the knowledge, attitudes and practices towards menstrual cycle and its problems: a comparative study of government and non-government adolescent school girls, International Journal Community Medicine and Public Health,4(4):973-981.

14. Haque S., Rahman M., Itsuko K., Mutahara M., \& Sakisaka K., (2014): Effect of a schoolbased educational intervention on menstrual health among adolescent girls in Bangladesh , BM journal ,4(7): 4607.

15. Harun O., Hakim A., \& Sartika L., (2016): Correlation of students' knowledge level about menstrual with dysmenorrhea handling effort ,International Journal of scientific and technology research ,5(2): 170-178.

16. Hennegan, J., \& Montgomery P., (2016): Menstrual Hygiene management Interventions Improve Education and Psychosocial Outcomes for Women and Girls in Low and Middle Income Countries, International Journal of Applied Research,5(2):101-105.

17. Kamel M., (2019): Knowledge and Attitude of Adolescent students toward premarital examination in secondary schools At Assiut city ,Thesis Submitted For Partial Fulfillment of the Requirements for Master Degree in Family and Community Health Nursing.

18. Kapoor J., Kaur N., Sharma M., \& Kaur S,(2017): A study to assess the effectiveness of pelvic rocking exercises on dysmenorrhea among adolescent girls, International Journal of Applied Research, 3(3): 431-434.

19. Kaur S., Sheoran P., \& Sarin J., (2015): Assessment And Comparison of Dysmenorrhea in Terms of Severity of Pain and Utilization of Non Steroid Anti-Inflammatory Drugs among Unmarried and Married Women , International Journal of Caring Sciences , 8 (3) : 737.

20. Khare D., \& Jain P., (2015): Effect of different exercise techniques on primary dysmenorrhea among higher secondary school girls, International Journal of Science and Research,5(12):1161-1164.

21. Khodarami, B., Masoomi, S., Faradmal J., Nazari M., \& Saadati M., (2015): The Severity of Dysmenorrhea and its Relationship with Body Mass Index among Female Adolescents in Hamadan, Iran ,Journal of midwifery and reproductive health ,3(4):444450.

22. Kiranmayi, P., Ponmathi P., \& Sivakumar V., (2016) : Comparison of Aerobic versus Stretching Exercise Programs on Pain and menstrual Symptoms in Subjects with Primary 
Dysmenorrhea, Journal Women's Health Care, 5 (4):1:5.

23. Kizilirmak A., Kartal B., \& Calpbinici P., (2019): Prevalence of dysmenorrhea in young women and their coping methods, International medicial journal ,16(2):1-5.

24. Kumar K., Konjengbam S., \& Devi H., (2016): Dysmenorrhea among higher secondary schoolgirls of Imphal West district, Manipur: A cross-sectional study ,Journal of Medical Society, 30 (1)38:43.

25. Mohammed H., Hassen N., \& Musa A., (2019): Dysmenorrhea and Associated Factors among Secondary School Students in East Hararghe Zone, Eastern Ethiopia , East African Journal of Health and Biomedical Sciences, 3(1):39-48.

26. Mole K., (2017): A study to assess the effectiveness of muscle stretching exercises on pain and discomfort during primary dysmenorrhea among nursing students in a selected college of nursing at Kannur, International Journal of Advanced Scientific Research,2(4):13-18.

27. Nooh A., (2016): Nature and prevalence of menstrual Disorders among Teenage Female Students at Zagazing University, Egypt ,Journal of pediatric and Adolescent Gynecology ,29(2):137-142.

28. Patel P., Karelia B., \& Piparva K., (2017): Dysmenorrhea prevalence ,impact and knowledge aspect of treatment in females of reproductive age in tertiary care teaching hospitals , International Journal of Pharmaceutical Sciences and Research, 7(11): 4556-4560.

29. Patil S., Mahanthshetty H., Supriya H., \& Mahendra M., (2019): Gynecological problems of adolescent girls attending to rural tertiary care center ,international journal reproductive ,conception ,obstetrics and geological ,8(7):1

30. Renuka K., \& Jeyagowri S., (2015): Stretching Exercise therapy and primary dysmenorrhea Nursing perspectives ,Journal of Nursing and Health Science ,4(3):1-4.

31. Saeed A., (2018): Associated clinical manifestations and self management approaches of primary dysmenorrhea among adolescent students in Erbil City, Iraq, Medicine Journal Babylon,15(2)150-154. 